\title{
Flavia Macías. Armas y política en la Argentina. Tucumán, siglo XIX. Madrid: Consejo Superior de Investigaciones Científicas. Colección América, 2014, 280 páginas.
}

$\mathrm{T}^{\circ}$ oda aparición de un libro tiene algo de celebratorio para el autor y los lectores. ¿Qué podríamos celebrar ante Armas y política en Argentina. Tucumán, siglo XIX de Flavia Macías? Un primer motivo se encuentra en el hecho de que su autora da muestras a través de él de un notable proceso de crecimiento intelectual individual, proporcionándonos como resultado una reflexión sólida, madura y estimulante sobre un tópico que ella ha rastreado a lo largo de varios años y a partir de cual realiza un nuevo aporte a ese proceso de renovación desde nuevos enfoques e interrogantes que tanto dinamismo otorgó al campo de la historia política en estas últimas décadas.

El texto se ve atravesado por diversos debates que han puesto en cuestión algunas tesis clásicas y que fueron proporcionando claves renovadas de lectura e interpretación. El núcleo central de Armas y política... gira, sin duda, alrededor de la compleja discusión en torno a la relación entre política y violencia, y, muy particularmente, sobre la figura polivalente del ciudadano. Si muchos análisis se volcaron a recuperar el papel institucional cumplido por ese actor en el ejercicio de su soberanía a través de la práctica electoral o del uso político de la calle, no tantos habían explorado en profundidad su rol como ciudadano en armas, involucrado en milicias o guardias nacionales, y altamente comprometido con la dinámica del Estado en conformación y su legitimidad soberana.

Pero para conducirnos hacia él, Macías elige hacerlo desde un espacio jurisdiccional específico: la provincia de Tucumán. Dicha elección no es casual ni ingenua ya que la misma nos introduce en otro de los planos de la política: el de la relación entre provincias/regiones y el de la conformación del Estado central. El texto pone en evidencia el dinámico juego desplegado desde la etapa posindependiente entre una experiencia jurisdiccional particular con

\footnotetext{
1 Investigaciones Socio-históricas Regionales-Universidad Nacional de Rosario/Nodo Centro de Estudios Sociales Regionales-Consejo Nacional de Investigaciones Científicas y Técnicas. Argentina. Correo electrónico: mbonaudo@, tower.com.ar
} 
diferentes espacios regionales a los que, en la década de 1850/60, se sumaría un poder central cuya sola presencia obligaría a reconfigurar el conjunto de relaciones de poder en la República. Desde esta dimensión la autora no solo nos permite comprender -a través de diferentes coyunturas que atraviesan el siglo XIX- la compleja dinámica de encuentros y desencuentros entre provincia/región, las permanentes reestructuraciones de vínculos y alianzas a las que dieron lugar sus enfrentamientos, sino también el papel jugado por los Estados provinciales en la conformación del Estado central y de la comunidad política republicana. Este debate ha permitido en los últimos años ciertos replanteos del problema y una clara superación de las interpretaciones precedentes. En esa dirección el libro ratifica una vez más la potencialidad de los estudios regionales para comprender los procesos de formación de los Estados nacionales en el siglo XIX.

Pero retornemos al nudo central porque en él subyace el aporte más relevante de la obra, el de ofrecernos una identidad ciudadana potente que a lo largo de los capítulos va desplegándose en todas sus dimensiones, desde la electoral hasta la armada, resignificando en cada caso los desafíos de un contexto altamente cambiante.

En el devenir del relato cabe destacar la enorme preocupación de Macías por no perder de vista la dinámica temporal dentro de la cual sus actores van internalizando y dando encarnadura a las nuevas lógicas de configuración de un orden liberal y republicano. Al colocar el foco en ese protagonista de las Guardias Nacionales, el ciudadano armado, el análisis de la propia trama institucional se potencia tanto al recuperar la dinámica propia de los poderes militares, en un área de antigua tradición militarista, como al precisar el juego de descentralización y centralización que los mismos experimentaron antes y después de la emergencia republicana. Pero al mismo tiempo, la historiadora logra dirimir en diversas coyunturas las conflictivas relaciones entre las incumbencias militares y los nuevos ordenamientos institucionales provinciales y nacionales, ya sea develando el "uso instrumental" del ciudadano armado al interior de los dispositivos electorales, ya sea legitimando a través del derechodeber de empuñar las armas la emergencia de un "nuevo" orden.

El relato, fuertemente sostenido por un trabajo documental de gran envergadura, va cobrando densidad a medida que la autora profundiza su búsqueda en torno a la dimensión militar de la vida pública y de la ciudadanía.

A través de sus argumentaciones no solo vamos recuperando las trayectorias precedentes de las milicias como cuerpos cívicos urbanos, auxiliando a los ejércitos revolucionarios, o su nacionalización a partir de la emergencia de las Guardias Nacionales y el enrolamiento en sus huestes de los "ciudadanos 
de la nación", o incluso las distancias que separaron a las Guardias de otros cuerpos de defensa como los ejércitos regulares -tanto en su composición como en sus concepciones de la propia defensa-, sino que profundizamos nuestras percepciones sobre el papel de la guerra y de las revoluciones en la configuración de un orden político.

$\mathrm{Al}$ interior de esas densas tramas hay dos dimensiones que nunca se desdibujan. Por una parte, una y otra vez destacan en la escena central las dos caras del ciudadano: la del individuo en armas y la del votante. Dos caras fuertemente articuladas no solo por la sanción de la ley electoral de 1863 que imponía la acreditación del enrolamiento para poder votar, sino porque desde su emergencia las Guardias Nacionales fueron un definido espacio de politización y de movilización de electores y, por ende, de relevancia en la construcción del poder político. Por otra, su capacidad para dar encarnadura a esos actores, ya sea reconstruyendo trayectorias, cruzando roles políticos y militares de las dirigencias, analizando la integración social y territorial de los cuerpos de milicias y guardias, a partir de un corpus de fuentes que sostienen hipótesis y tesis.

El libro tiene una última condición positiva, no se cierra sino que se proyecta hacia adelante dejando a los investigadores y lectores pistas abiertas para explorar. Queda entonces en sus manos la oportunidad de darle continuidad. 